\title{
Study on the Application of Multimedia Technology on College Physical Education Teaching
}

\author{
Wei Liu \\ Hunan Vocational College of Modern Logistics, Changsha, Hunan, 410131
}

Keywords: multimedia technology; college physical education; application research

\begin{abstract}
With the continuous development of our country's education, the position of physical education teaching is becoming more and more important in college teaching system. High-level physical education teaching can not only effectively enhance the system of undergraduates, but also foster the strong will of students and promote students' comprehensive and healthy development. However, due to the impact of traditional teaching concepts, many colleges and universities in our country have low levels of physical education, which affects the overall development of college students' health to a certain extent. Therefore, in the context of the new era, major college sports teaching workers must further strengthen the emphasis on physical education, especially the application of multimedia technology in physical education, so as to maximize the level of physical education and promote the healthy development of students. This paper focuses on the analysis of the application of multimedia technology in physical education for reference by relevant persons.
\end{abstract}

\section{Introduction}

With the continuous development of information technology in China, the application of multimedia technology in physical education has become more and more extensive, which has greatly improved the teaching efficiency and teaching level. However, in the actual investigation, it is found that many colleges and universities in the application of multimedia in physical education teaching is not very satisfactory, to a certain extent, affecting the upgrading of college sports teaching, thereby affecting the overall development of college students' health. Therefore, under the continuous deepening of China's quality education reform, all colleges and universities in physical education should change the traditional concept of physical education, and strengthen the application of multimedia technology in physical education so as to effectively improve the efficiency of physical education teaching and teaching level in order to Maximize the health of college students, cultivate the unyielding will of college students, and achieve the goal of quality education.

\section{The Advantages of Multimedia Technology in College Physical Education Teaching}

In college physical education, multimedia can use a variety of forms to present teaching content, which can largely mobilize students' curiosity and curiosity, and make students have a strong interest in physical education. For example, tactical cooperation is an important teaching content in the process of basketball teaching in colleges and universities. However, students lack understanding of tactical cooperation such as cover and pass. In the traditional physical education teaching mode, teachers need to put a lot of energy and time to carry out theoretical explanations, and students will also be more nervous during the practice process, so it is difficult to produce good teaching effects on the teaching of these contents, especially difficult. Let students have a deep impression on these tactical cooperation. In multimedia-assisted teaching, teachers can use game software to deepen students' understanding and understanding of basketball tactical cooperation. By using these softwares to simulate the game environment with real basketball game rules, students can play basketball rules in entertainment and The tactical application provides an intuitive understanding so that the content that these instructors can demonstrate is more easily grasped by the students. 
Real-time communication technology is an important feature of multimedia-assisted instructional technology. Full utilization of this feature and the full use of its advantages make it possible for teachers and students in college sports teaching to conduct more timely and effective communication and exchange. This is for teachers. Understanding the learning needs and learning characteristics of students provides a favorable environment and conditions. And the realization of this advantage is conducive to solving the problem of the traditional college physical education teaching due to the large number of students, the teacher is difficult to understand the students one by one and the lack of communication and communication with the students.

The application of multimedia-assisted teaching technology in college physical education can enrich the content of college physical education and at the same time enable the optimization and sharing of these teaching contents. On the one hand, this sharing is reflected in the Internet and the classroom, that is, teachers can collect and display information related to the teaching content in the Internet during the development of physical education activities. Compared with traditional methods of information collection, the acquisition of such teaching resources has lower cost and higher efficiency; on the other hand, this sharing is also reflected in universities and colleges. That is, the teaching content collected by a college PE teacher can be shared with teachers in other schools via the Internet. This sharing is two-way and mutual. Based on this, college PE teachers can obtain less effort. A large amount of high-quality teaching materials and more attention can be paid to the selection and teaching of these high-quality teaching materials, which is of great significance for improving teaching efficiency. Of course, the application value of multimedia assistive technology in college physical education teaching is not only reflected in the above aspects, but also in the ability to cultivate students' independent learning ability, provide students with personalized learning space, break the time and space restrictions in the teaching process, and promote There are many aspects such as the diversification of physical education teaching methods. Therefore, as a physical education teacher in colleges and universities, it is necessary to fully understand the application value of multimedia-assisted instructional technology, and based on this, improve the application ability of its own multimedia-assisted instructional technology in order to use multimedia. Improve the quality of physical education in colleges and universities under the premise of assisting the advantages of teaching technology.

\section{The Application of Multimedia Technology in Physical Education}

The application of multimedia technology can not only effectively improve the students' interest, but also effectively break through the difficulties in physical education and improve the teaching effect. Therefore, in the new era, college teachers should strengthen the application of multimedia technology in physical education.

The animation software can move, rotate, freeze, and play slowly according to the user's wishes. This will help the teaching of complex and instantaneous sports activities. Therefore, in physical education, physical education teachers should strengthen the application of animation. First of all, teachers of physical education teaching should use relevant animation design software to design sports teaching animations according to the contents of physical education teaching. Animation should be as vivid as possible so as to fully mobilize the enthusiasm of students. Secondly, in the actual teaching process, teachers should pay attention to the playing skills. For example, in the case of the trainer-style long jump, the teacher should first play at normal speed, so that the students can have a general impression in their heads, and then start $1 \mathrm{x}, 2 \mathrm{x}$ and $3 \mathrm{x}$ slow play allows students to fully understand every step of the action. In the end, teachers should play in some key areas, and at the same time, the teacher will explain it. This can visualize abstract sports actions and deepen students' understanding of the movement's actions.

In physical education teaching, there are some sports facilities on-site facilities, teachers and students can not perform the actual complete training, so to a certain extent, affect the effectiveness of college sports teaching, so college sports teachers should strengthen the application of simulation software. For example, football rule teaching is used as an example. Football teaching teachers can use those football simulation software to show the football match scene, let students make their own 
referees and players, use the keyboard to judge the foul situation in the screen, and the computer within the specified time. The grades of the referees will be scored, so that through multimedia presentations and teacher explanations, students' understanding of the ball referee law will be deepened, and students' mastery of football rules will be effectively improved.

In traditional physical education, students cannot see their own movements, so that they can't improve their sports activities based on their actual actions, which affects the effectiveness of physical education to a certain extent. Therefore, in modern physical education teaching, teachers should strengthen the use of video equipment in physical education classrooms, especially in sports training, carefully record each student's movements, and then the teacher guides students to watch the video to see their own movements, and Correcting your own actions according to the normative actions, in order to maximize the effect of physical education in colleges and universities.

The application of film and television propaganda video can not only effectively stimulate students' interest in learning sports, but also can effectively improve the effect of physical education. Therefore, in practical teaching, physical education teachers should strengthen the application of film and television and sports videos. First of all, physical education teachers should choose the right match video based on the teaching content, and can't play video without aim, which will greatly affect the play effect of the game video. Secondly, college sports teaching teachers should also grasp the playing time of teaching videos. (1) Before the teaching, some game videos related to teaching materials can be played, which can attract students' interest and stimulate their enthusiasm for learning; (2) There should be some short little videos interspersed in the teaching process. This will not only delay time but also effectively improve teaching effectiveness. In a word, the application of teaching videos can effectively arouse students' interest in learning, and at the same time, it can effectively improve teaching effectiveness.

The lack of multimedia equipment is a common problem faced by colleges and universities in carrying out multimedia-assisted teaching. There are two main reasons for this kind of teaching situation: On the one hand, the multimedia hardware facilities used in college sports teaching are relatively expensive. On the other hand, the content of college sports teaching has high standards for the quantity and quality of multimedia equipment. Quality education clearly requires the addition of modern educational technology in teaching. The management of universities should clearly understand the current state of modern education, increase the investment in computer hardware facilities, and complete the hardware and software of multimedia technology. In addition, the application of multimedia technology in college sports teaching is limited by the site to a certain extent. Multimedia-assisted teaching is generally conducted indoors through the teaching platform for teaching practice activities. The equipment is limited and most of them are fixed. Outdoor sports teaching activities cannot be realized using multimedia. Teaching imposes constraints on the transfer of professional-related instructional knowledge. While increasing hardware facilities, we must also increase the investment in physical education software facilities. Teachers should actively and diligently develop practical physical education software.

The use of any teaching method must be based on a certain degree of "degree". It must not be because of the superiority of multimedia technology and the blind use of multimedia-assisted instruction. Otherwise, it will have a bad influence on the teaching effect. Modern educational technology uses advanced technology and equipment as the material basis to realize the three-dimensionalization of sports skills and knowledge and stimulate students' enthusiasm and creativity in learning. In the extensive use of multimedia-assisted teaching, it must be organically combined with traditional teaching methods in a timely manner. The integration of tradition with the times can not only ensure the impartment of basic theoretical knowledge, but also ensure the improvement of teaching quality, complement each other, and improve together. And improve college sports teaching. The traditional teaching model is single and backward, and the perfect multimedia CAI can effectively eliminate students' negative emotions towards physical education. Through multilateral, flexible, and fresh multimedia techniques, students' senses can be stimulated to the greatest extent and students' curiosity can be stimulated. The combination of sound mapping and audio-visual teaching means that students can understand boring sports theory knowledge and 
skills, and can also feedback the students' learning status in time through the video function, so that the entire physical education activity can be rationally and systematically implemented. Adjustments. Improve multimedia CAI, and gradually realize indoor and outdoor unrestricted teaching activities. Through human-machine dialogue, organize physical education activities according to specific venue conditions.

\section{Conclusion}

The application of multimedia technology in college physical education classroom teaching has realized the modernization and scientization of college education, and also opened up a new path for improving the quality and efficiency of college sports teaching. Multimedia-assisted teaching is a new type of teaching mode. The application of multimedia technology in physical education is a systematic project. Teachers and students need to work together to achieve teaching goals with the participation of multimedia technology. We still need to work hard to explore and develop more and more effective teaching methods and teaching models to speed up the historical process of university reform.

\section{References}

[1] Yue Shurui. Application of Modern Multimedia Technology in College Physical Education [J]. Journal of Nanchang College of Education, 2010, 25(5): 65-82.

[2] Wei Jia. Application of Multimedia Technology in College Physical Education [J]. Journal of Chifeng University, 2011, 6(6): 146-147.

[3] Zhou Xiaojing. Research on the Application of Multimedia Technology in College Physical Education [J]. Culture \& Sports Goods and Technology, 2011(7):114-116.

[4] Ni Wei. The Practical Exploration of Multimedia in College Physical Education [J]. Education and Occupation, 2009(14):143-144.

[5] Wu Changjiang. Analysis of the Application of Multimedia Technology in Track and Field Teaching in Universities [J]. China New Technology and Products,2009(1O):239. 